\title{
TOLERÂNCIA, LEGITIMAÇÃO POLÍTICA E RAZÃO PÚBLICA
}

\author{
Denílson Luis Werle \\ Universidade Federal de Santa Catarina
}

\begin{abstract}
The aim of this paper is to present the concept and the different conceptions of toleration developed in modernity, examining the question of the limits of toleration. It is to be the argument that the concept of toleration, to attain some configuration and content, is normatively dependent on the idea of democracy: the delimitation of toleration requires the specification of a principle of political legitimacy based on public deliberation and justification according to which the standards, practices and institutions that organize the common life may be justifiable in the light of good reasons acceptable to all citizens. The central ideia of the article is that the delimitation of toleration is not a theoretical-moral task, but a practical-political task to be carried on by the citizens through democratic procedures of public deliberation.
\end{abstract}

Keywords: Limits of toleration, political legitimacy, public justification.

Resumo: O objetivo do artigo é apresentar o conceito e as diferentes concepções de tolerância desenvolvidas na modernidade, examinando a questão dos limites da tolerância. Parte-se do argumento de que o conceito de tolerância, para ganhar uma configuração e conteúdo, é normativamente dependente da ideia de democracia: a delimitação da tolerância exige a especificação de um princípio de legitimação política fundamentado na deliberação e justificação públicas segundo o qual as normas, práticas e instituições que organizam a vida comum possam ser justificáveis à luz de boas razões aceitáveis por todos os cidadãos. A ideia central do artigo é que a delimitação da tolerância não é uma tarefa teórico-moral, mas sim uma tarefa prático-política a ser levada adiante pelos próprios cidadãos por meio de procedimentos democráticos de deliberação pública.

Palavras-chave: Limites da tolerância, legitimidade política, justificação pública.

A tolerância, seja como virtude moral individual, ou valor político das instituições ou ideia da própria razão prática, tem, sem dúvida, uma importância imensa no contexto das sociedades democráticas modernas, 
cujos cidadãos se defrontam continuamente com a tarefa de encontrar formas de conciliar as reivindicações morais diversas e conflitantes que indivíduos e grupos sociais, culturais, étnicos e religiosos dirigem unas aos outros e às instituições que organizam a vida comum. Fórmulas simples do tipo "viva e deixe viver", "a liberdade de um acaba onde começa a liberdade do outro", ou atitudes de laissez faire ou de ataraxia são geralmente tomadas no senso comum como expressões de mentalidades abertas e tolerantes. Contudo, tais expressões além de serem insuficientes, são na verdade indesejáveis e ofensivas, pois expressam muito mais atitudes de indiferença moral do que propriamente de tolerância. No que se segue pretende-se examinar melhor o conceito de tolerância e as diferentes concepções de tolerância, procurando tornar mais claro o que significa estar diante de uma questão de tolerância, qual o seu sentido e como estabelecer os limites da tolerância. Afina, quais as razões que justificam a tolerância uma vez que qualquer compreensão e configuração histórica concreta deste conceito pode ter a marca da intolerância em relação àqueles que são chamados, talvez de maneira arbitrária, de intolerantes? Aos olhos de alguns, a tolerância parece ser nada mais do que um artifício retórico nas lutas políticas pelo poder, nas quais cada parte pretende expressar um nível mais elevado de legitimidade e imparcialidade na definição da diferença entre tolerância e intolerância. A questão que se coloca para a filosofia política é quem define os limites do tolerável e o intolerável e, uma vez que na própria definição pode estar inscrita a marca da intolerância e da exclusão arbitrária, como fazê-lo sem recorrer a uma doutrina moral, filosófica, religiosa abrangente ou a uma concepção ampla de vida boa?

Nesse sentido, parece-nos muito apropriado o título que Forst (2003) dá a sua ampla investigação sobre o discurso histórico e o pensamento político acerca da tolerância: tolerância no conflito [Toleranz im Konflikt]. $\mathrm{O}$ argumento de Forst é o de que o conceito de tolerância, para ganhar algum conteúdo e significado mais concreto, é normativamente dependente de um outro princípio ou conceito, o de democracia. A definição dos limites do tolerável/intolerável, numa sociedade democrática, passa pela especificação de um princípio de justificação pública baseado na reciprocidade e na universalidade, segundo o qual as normas, práticas e instituições político-jurídicas que organizam a vida social possam ser justificadas à luz de razões aceitáveis por todos ou que ninguém poderia razoavelmente rejeitar, na já conhecida expressão de Thomas Scanlon. Depois 
de apresentar o conceito e as diferentes concepções de tolerância desenvolvidas na modernidade (I) pretende-se analisar os fundamentos de um princípio de legitimação política fundamentado na deliberação e justificação públicas por meio da ideia de "uso público da razão" desenvolvida por Habermas em suas reconstrução das articulações conceituais entre Estado de direito e política deliberativa. A ideia habermasiana de justificação pública e de um princípio de legitimação democrática deliberativa, fundamentado no uso público da razão por parte de cidadãos livres e iguais (e sua tradução social e institucional na forma de uma política deliberativa) permite visualizar mais especificamente como esse princípio de justificação pública funciona (ou, ao menos, pode funcionar) nas democracias. A ideia central do artigo é que a delimitação da tolerância não é uma tarefa teórico-moral, mas sim uma tarefa prático-política a ser levada adiante pelos próprios cidadãos por meio de procedimentos democráticos de deliberação pública (II).

\section{I - Conceito de tolerância e concepções de tolerância}

Segundo Forst (2003) a expressão "tolerância no conflito" pode ser entendida de quatro modos. Primeiro, a tolerância é uma atitude e uma prática que é exigida somente no conflito. Ela emerge como uma práxis cuja especificidade não é resolver de uma vez por todas as controvérsias, mas de manter a oposição de convicções, interesses, valores e práticas, porém retirando-lhes seu potencial destrutivo das relações de convivência. $\mathrm{O}$ que a tolerância permite esperar é que seja possível a convivência no dissenso entre indivíduos e grupos diferentes, sem que esse dissenso se torne uma luta de vida ou morte ${ }^{1}$.

Tolerância no conflito significa também, em segundo lugar, que a exigência por tolerância não se encontra para além das controvérsias em uma sociedade concreta, mas surge de seu interior, de modo que a configuração concreta da tolerância sempre aparece vinculada ao contexto de lutas sociais. Isso significa que a própria tolerância apresenta-se como uma posição a ser defendida nos conflitos: seus defensores têm de tomar partido nas controvérsias sociais no sentido de favorecer uma tolerância recíproca,

\footnotetext{
1 "As partes em conflito alcançam uma atitude de tolerância porque percebem que às razões para a recusa recíproca se contrapõem razões para a aceitação recíproca que não superam as primeiras, mas, não obstante, recomendam a tolerância; mais do que isso, a exigem" (FORST, 2003, p. 12).
} 
mesmo quando a estrutura e os fundamentos normativos da tolerância repousem no princípio da imparcialidade. Ainda que aspire a produzir algum equilíbrio, a demanda por tolerância não é neutra: ela se coloca como uma posição nas lutas sociais. Se acompanharmos a "evolução" da ideia e prática da tolerância podemos ver inscrita nela a própria história das diferentes lutas sociais na modernidade (FORST, 2003).

Disso deriva um terceiro significado. A tolerância não apenas é exigida no conflito, como também é objeto dos conflitos. $O$ conceito não apenas não é unívoco, como também controverso, não apenas no sentido de que uma mesma instituição, lei, política, norma ou prática pode ser vista por alguém como expressão de tolerância e por outro como expressão de intolerância, mas também no sentido de que se discute se a própria tolerância é algo bom e louvável. Como pode ser observado na vasta literatura sobre a tolerância, para alguns, trata-se de uma virtude louvável (exigida por Deus, pela Moral, pela razão ou, pelo menos, pelo bom senso e prudência política), enquanto que para outros ela é um gesto condescendente e paternalista, potencialmente repressivo; para alguns, é expressão da autocertificação e firmeza de caráter, para outros, uma atitude da incerteza, permissividade e fraqueza; para alguns, é expressão do respeito pelo outro e inclusive de valorização daquele que é diferente de nós, para outros, é uma atitude de indiferença, ignorância e desprezo. Exemplos dessas atitudes são numerosos na literatura sobre a tolerância. A título de ilustração, por um lado, temos os elogios que Voltaire, Bayle, Lessing, Locke e Mill, fazem à virtude da tolerância como sendo a expressão da humanidade autêntica, da civilidade entre pessoas razoáveis e de uma cultura mais elevada; por outro, a sempre mencionada crítica de Goethe, apresentada em suas Máximas e Reflexões. "tolerância deveria ser uma disposição de espírito [Gesinnung] apenas passageira: ela precisa levar ao reconhecimento. Tolerar [Dulden] significa ofender" (apud FORST, 2003ํㅜ p. 14)²; as afirmações de Benedetto Croce de que os tolerantes "nem sempre foram os espíritos mais nobres e heróicos. Freqüentemente houve entre eles demagogos e indiferentes. Os espíritos vigorosos matavam e iam em direção à morte” (apud BOBBIO, 1992, p. 205); as desconfianças dos "frankfurtianos" Marcuse e Fromm, para quem a

\footnotetext{
${ }^{2}$ Como veremos adiante, a crítica de Goethe dirige-se a uma concepção muito específica de tolerância: a chamada concepção permissiva ou condescendente [Erlaubnis-Konzeption], que não abrange 0 espectro mais amplo de expectativas normativas associadas ao conceito de tolerância.
} 
tolerância é um "virtude repressiva", que impede a eclosão das forças disruptivas: ela mascara as relações de exclusão política e social e, como virtude política da democracia representativa burguesa, neutraliza em favor do status quo toda forma de dissenso e impossibilita a formação autônoma do juízo, impedindo a manifestação das forças sociais emancipatórias.

Dessas diferenças acerca da aplicação e do valor do conceito de tolerância, decorre um quarto sentido para a expressão tolerância no conflito. Embora seja possível falar de um conceito geral de tolerância, existem diferentes concepções de tolerância e uma gama de fundamentações bem diferentes para a tolerância: razões de ordem pragmática, ética, moral. Para Forst, o cerne do conceito de tolerância reside em três componentes: objeção, aceitação e rejeição. "Primeiro, uma crença ou prática justificada deve ser julgada como falsa ou ruim para poder ser uma candidata à tolerância; segundo, à parte dessas razões para objeção, devem existir razões do por que ainda seria errado não tolerar essas crenças ou práticas falsas ou ruins - isto é, razões de aceitação. Tais razões não eliminam as razões de objeção; antes, são situadas numa dado contexto. E, terceiro, deve haver razões para a rejeição que marcam os limites da tolerância” (FORST, 2007, p. 217; cf. também FORST, 2004).

Essa definição geral recebe uma configuração concreta quando se coloca a tarefa prática de explicitar o que deve ser tolerado, por quais razões e como lidar com os limites do tolerável e intolerável. $\mathrm{Na}$ modernidade, podemos falar de pelos quatro concepções básicas legítimas de tolerância na modernidade, que mostram como o conceito de tolerância adquire certo conteúdo:

(1) a concepção permissiva ou condescendente (ErlaubnisKonzeption). Segundo essa concepção, a tolerância caracteriza-se por uma mistura complexa de liberdade e dominação, de inclusão e de exclusão, de reconhecimento e de desrespeito. A tolerância é entendida como uma relação entre uma autoridade (ou uma maioria) e as representações de valor de uma minoria (ou várias minorias). Tolerância significa aqui que a autoridade (ou a maioria) concede à minoria (ou minorias) a permissão de viverem de acordo com suas crenças, sob a condição de que a minoria não coloque em questão ou ameace a hegemonia da autoridade ou da maioria. Enquanto a manifestação de suas diferenças permanecer dentro de certos limites e no âmbito privado e os grupos minoritários não reivindicarem igual status público e político para suas crenças em face da autoridade, eles podem ser 
tolerados tanto do ponto de vista pragmático quanto do ponto de vista normativo. Pragmático no sentido de que essa concepção de tolerância é vista como a que apresenta os menores custos, e não perturba a ordem social e a paz civil que a cultura dominante define. E do ponto de vista normativo, a autoridade dominante pode considerar infrutífero ou equivocado forçar os membros dos grupos minoritários a abandonarem suas crenças e práticas mais profundas. Enfim, nessa primeira concepção, tolerância significa que a autoridade ou a maioria que possui o poder e a possibilidade de intervir e obrigar as minorias à conformidade opta por "tolerar" as diferenças, sob a condição de que as minorias não afrontem ou amecem a posição de poder da autoridade hegemônica. Trata-se de uma concepção de tolerância não recíproca, entendida como permissio mali, uma forma de reconhecimento que concede às minorias certas liberdades - o que nos permite falar que tal concepção apresenta um viés emancipatório, se comparada com outras situações de intolerância e perseguição às minorias - contanto que sejam exercidas dentro dos "limites do tolerável", definidos à luz da cultura dominante - o que nos remete, por sua vez, ao lado repressivo (MARCUSE, 1965) e disciplinador dessa concepção, pois ser tolerado aqui significa aceitar uma posição subalterna, desprivilegiada, de cidadão de segunda classe. Nesse sentido, ela produz identidades e formas de vida culturais estigmatizadas, que ao mesmo tempo são incluídas e excluídas socialmente (BROWN, 2000).

(2) a concepção da tolerância como coexistência (KoexistenzKonzeption). Semelhante à primeira, a tolerância é fundamentada de forma pragmática-instrumental. A tolerância é valorizada somente como um meio apropriado para evitar o conflito e como forma para cada indivíduo ou grupo realizar seus objetivos próprios. Modifica-se, contudo, a constelação entre sujeitos e objetos da tolerância. Não se trata mais da oposição entre autoridade (ou maioria) e minorias, mas da oposição de grupos fortes mais ou menos iguais em poder, que chegam à conclusão (contingente e dada pela correlação de forças) de que a realização de seus próprios interesses e valores depende da tolerância recíproca. Eles preferem a coexistência pacífica no conflito e aderem de boa vontade a um compromisso recíproco em torno das regras de um modus vivendi que admite uma convivência pragmáticoestratégica entre os diferentes indivíduos e grupos. Nessa concepção, a relação de tolerância tem um caráter horizontal e fundamenta-se numa necessidade prática, sem qualquer aspecto normativo. Fundamentada de modo estratégico e instrumental, ela não implica nenhuma forma ética ou moral de 
reconhecimento recíproco: a relação de tolerância altera-se conforme vão se modificando as relações de poder e força na sociedade.

Nas duas concepções apresentadas até aqui, a tolerância se situa no contexto de uma práxis política. A tolerância é uma forma de política estatal orientada para a manutenção da paz, da ordem pública, da estabilidade, do rule of law ou da constituição, e, portanto, para a conservação de determinadas relações de poder. A tolerância é entendida no interior do processo moderno de racionalização do poder político, isto é, está inserida no processo de autonomização do poder político frente à autoridade religiosa e de estabelecimento de fontes seculares de legitimação. A prática da tolerância é, desde o início, uma política do poder, que surge em decorrência de uma necessidade prática de cooperação. E como tal, pode carregar consigo a marca da arbitrariedade. Porém, a tolerância não se esgota nisso. Intimamente vinculada à racionalização do poder, mas também em oposição a ele, a tolerância é situada no processo moderno de racionalização da moral, no movimento teórico (com conseqüências institucionais) de refinamento dos argumentos normativos para a tolerância. Trata-se de perceber como ocorre uma racionalização dos argumentos morais a favor da tolerância que se contrapõe não apenas às fundamentações religiosas e metafísicas do que é a vida boa, mas que pretende também oferecer padrões normativos de justiça para a própria racionalização do poder político (cf. KOSELLECK, 1999). O desenvolvimento do discurso da tolerância é também o discurso sobre a formação de uma nova consciência ético-moral, uma nova autocompreensão da identidade ética, jurídica, política e moral das pessoas (Forst, 2003a: 18, 19). Isso pode ser visto nas outras duas concepções de tolerância típicas da modernidade, nas quais tolerância é entendida numa perspectiva intersubjetiva, como uma atitude e uma virtude exigidas ${ }^{3}$ das pessoas nas relações sociais mais amplas.

(3) em contraposição às duas primeiras concepções, a tolerância pode ser entendida como uma forma de respeito mútuo fundamentada moralmente: a tolerância como respeito (Respekt-Konzeption). Aqui, a relação de tolerância parte do pressuposto de que os indivíduos respeitam um ao outro como pessoas autônomas, como membros com igualdade de

\footnotetext{
3 "Exigidas" não meramente no sentido de apelar a uma boa vontade dos cidadãos, mas sim, exigidas institucionalmente, pelo sistema de direitos fundamentais que formam o Estado de direito democrático (ou as democracias constitucionais).
} 
direitos de uma comunidade política constituída na forma do Estado de direito. Embora existam diferenças significativas e, muitas vezes, incompatíveis nas convicções éticas sobre a vida boa e nas práticas culturais dos indivíduos e grupos, estes se reconhecem reciprocamente como autores moralmente autônomos de suas próprias vidas e se reconhecem reciprocamente como iguais do ponto de vista moral e político no sentido de que a seus olhos a estrutura básica comum da vida político-social é orientada por normas e princípios que todos os cidadãos poderiam igualmente aceitar. Segundo Forst (2003a), o aspecto fundamental dessa concepção de tolerância consiste no respeito à autonomia moral dos indivíduos e ao seu "direito à justificação" [Rechts auf Rechtfertigung] de normas que pretendem ter uma validade social universal e recíproca. $\mathrm{O}$ importante nessa concepção não é que os indivíduos valorizem ou estimem reciprocamente as concepções do bem, valores, interesses e práticas. A tolerância como respeito não passa pela formação de um juízo sobre as concepções e formas de vida diferentes: o que é respeitado é a dignidade moral e a autonomia da pessoa; e toleradas são as convicções e ações dessa pessoa.

(4) Indo além da concepção da tolerância como respeito, na discussão contemporânea sobre multiculturalismo e as lutas por reconhecimento das diferenças, desenvolveu-se uma quarta concepção de tolerância, fundamentada na valorização e estima (Wertschätzungs-Konzeption). Ela implica uma forma mais exigente de reconhecimento do que a tolerância como respeito moral. Agora, tolerância não significa apenas respeitar os membros de outras comunidades culturais e religiosas como iguais do ponto de vista político-jurídico, mas também valorizar e estimar do ponto de vista ético suas convicções e práticas. A relação da tolerância e a vida em comum consistem na formação de um juízo de valor e no reconhecimento do valor ético das convicções e culturas diferentes.

A distinção entre as várias formas de tolerância é obviamente muito esquemática, e na maioria das vezes, em situações concretas, observamos uma sobreposição e complementaridade entre elas. Mas o que nos importa aqui é perceber o quanto a tolerância é um conceito dependente normativamente de outros conceitos para ganhar uma configuração mais concreta. Mais precisamente, segundo Forst $(1999,2003 a)$ numa sociedade democrática, a tolerância depende de um princípio de justificação pública, que torne possível explicitar quais razões (pragmáticas, éticas, morais, jurídicas) para a tolerância são convincentes em quais contextos. A questão da tolerância, a delimitação de 
suas forma e conteúdos, remete-nos, portanto, à discussão sobre como a relação política deve ser entendida numa sociedade democrática.

A tolerância tem de ser pensada em conjunto com o conceito de democracia e de justiça política. E no contexto de sociedades democráticas sujeitas ao fato do pluralismo isso significa que os limites da tolerância devem ser demarcados não a partir do padrão transcendente de valores morais prévios à política, mas pelos próprios cidadãos livres e iguais que devem poder se autocompreender como autônomos politicamente, isto é, simultaneamente como destinatários e co-autores das regras de convivência a que vão ser coagidos a se submeterem. Trata-se do princípio moderno de legitimação, fundamentado na autonomia política de cidadãos livres e iguais que, por meio do uso público da razão, procuram convencer-se recíproca e racionalmente sobre quais as melhores regras e princípios que devem regular a vida em comum. Essa ideia está na base da autocompreensão normativa do Estado de direito democrático, que, por um lado, diante do pluralismo de concepções abrangentes do bem, procura se fundamentar numa neutralidade de justificação do exercício de um poder político que se tornou independente de qualquer cosmovisão religiosa ou metafísica; por outro, abre espaço à autodeterminação democrática dos cidadãos que, com direitos fundamentais individuais, passam a dispor, em princípio (isto é, pelo menos formalmente) de iguais oportunidades de participação no exercício da soberania popular (cf. HABERMAS, 2001). Assim, para evitar uma delimitação repressiva da tolerância por parte de uma autoridade secular benevolente, são necessários argumentos convincentes e aceitáveis, de modo igual, por todas as partes ${ }^{4}$. Mas como entender a legitimação política por meio do uso público da razão? $\mathrm{O}$ procedimento democrático de formação deliberativa da opinião e da vontade sugerido por Habermas apresenta um bom caminho para pensar a questão dos limites da tolerância. A ideia que me parece central na concepção de uso

\footnotetext{
${ }^{4}$ Rawls expressa uma ideia semelhante ao explicitar o princípio liberal de legitimidade: "nosso exercício do poder político é próprio e, por isso, justificável somente quando é exercido de acordo com uma constituição cujos elementos essenciais se podem razoavelmente esperar que todos os cidadãos endossem, à luz de princípios e ideais aceitáveis para eles, enquanto razoáveis e racionais. Esse é o princípio liberal da legitimidade. E, como o exercício do poder político deve ser legítimo, o ideal de cidadania impõe o dever moral (e não legal) - 0 dever de civilidade - de ser capaz de, no tocante a essas questões fundamentais, explicar aos outros de que maneira os princípios e políticas que se defende e nos quais se vota podem ser sustentados pelos valores políticos da razão pública. Esse dever implica também a disposição de ouvir os outros, e uma equanimidade para decidir quando é razoável que se façam ajustes para conciliar seus próprios pontos de vista com os outros" (RAWLS, 2000, p. 266).
} 
público da razão, quando pensada na questão dos limites da tolerância, é que a delimitação do tolerável e intolerável é muito mais uma tarefa prática-moral, do que uma questão teórica conceitual, isto é, não pode ser resolvida por alguma teoria moral que prescreva princípios morais abstratos prévios à política, mas tem de ser resolvida pelos próprios cidadãos nas situações de conflito. O que podemos reconstruir são os procedimentos desse uso público da razão que permitam aos cidadãos levarem adiante essa tarefa.

\section{II - Legitimação política e estrutura da razão pública.}

De um modo esquemático, pode-se dizer que Habermas defende uma forma de republicanismo kantiano que se auto-interpreta como uma justificação pós-metafísica e não religiosa dos fundamentos normativos do Estado de direito democrático. Para Habermas (2007, p. 163), “o Estado constitucional democrático, que depende de uma forma deliberativa de política, representa, em geral, uma forma de governo pretensiosa do ponto de vista epistêmico e, de certa forma, sensível à verdade”. Sua legitimidade depende de pretensões de validade contestáveis em público, portanto de um "uso público da razão" no qual devem ser levados em conta todos os temas, posicionamentos, informações e argumentos que encontrarem ressonância na esfera pública (informal e formal) e contribuírem de alguma forma para a mobilização de certas decisões implementadas pelo poder político.

Esse uso público da razão pode ser reconstruído em duas linhas de argumentação na teoria de Habermas. Primeiro, na reconstrução da sua concepção intersubjetiva do conceito kantiano de autonomia a partir dos pressupostos pragmáticos da ação e de liberdade comunicativas. Habermas condensa essas qualidades no princípio do discurso, segundo o qual somente são válidas as normas de ação às quais todos os possíveis atingidos poderiam dar o seu assentimento, na qualidade de participantes de discursos racionais (HABERMAS, 1997. v.1, 142). Numa segunda linha de argumentação, numa abordagem apoiada nas teorias sociológicas da democracia e do direito, o princípio do discurso é "traduzido" para as condições do procedimento deliberativo de legitimação próprio do Estado de direito democrático, segundo o qual os próprios cidadãos membros de uma comunidade jurídica concreta podem chegar, no uso de sua razão na esfera pública (informal das redes anônimas e formal do sistema político-institucional) e na sociedade 
civil, a uma autocompreensão de si mesmos a propósito das bases normativas de sua vida em comum ${ }^{5}$.

O princípio do discurso satisfaz uma necessidade pós-metafísica de justificação explicitando "o sentido da imparcialidade de juízos práticos", servindo como uma procedimento de teste para a fundamentação de normas de ação em geral (éticas, morais e jurídicas). Segundo Habermas, "este princípio possui certamente um caráter normativo”, mas ainda não é um princípio moral, pois "conta apenas com uma intersubjetividade de ordem superior" situada num "nível de abstração que, apesar de seu conteúdo normativo, ainda é neutro em relação ao direito e à moral" (HABERMAS, 1997, I). Pelo fato de não poder mais recorrer a conceitos fortes de natureza, que extraem os elementos normativos de uma constituição do ente ou da subjetividade, a teoria discursiva de Habermas "procura obter um conteúdo normativo da própria prática de argumentação, da qual nos sentimos dependentes sempre que nos encontramos numa situação insegura - não apenas como filósofos ou cientistas, mas também quando, em nossas prática comunicativa cotidiana, a quebra de rotinas nos obriga a parar um momento e refletir, a fim de nos certificarmos reflexivamente acerca de expectativas justificadas” (HABERMAS, 2007, p. 96).

O ponto de partida de um princípio de justificação pós-metafísico encontra-se naqueles pressupostos pragmáticos inevitáveis nos quais os participantes da argumentação têm de se apoiar implicitamente quando decidem participar de "uma busca cooperativa" da verdade, a qual assume a forma de uma disputa por melhores argumentos. Impera nessa busca a "coerção não-coercitiva" do melhor argumento, que tem de ser alcançado em discursos racionais nos quais os participantes assumem o ônus de idealizações contrafáticas. Os pressupostos pragmáticos inevitáveis mais importantes são: inclusividade, distribuição simétrica das liberdades comunicativas; condição de franqueza, ausência de constrangimentos externos ou internos da estrutura da argumentação (HABERMAS, 2007, p. 97).

O importante para Habermas ${ }^{6}$ é que não se pode extrair deste conteúdo normativo dos pressupostos da argumentação regras morais

\footnotetext{
${ }^{5}$ No que se segue, analiso os aspectos normativos da noção de uso público da razão, deixando para outra ocasião a análise do conceito de política deliberativa e os diversos aspectos de sua tradução político-institucional.

${ }^{6}$ É o que vai diferenciá-lo da tentativa de fundamentação última de Apel.
} 
deontológicas do tipo: "dever de tratar a todos como iguais" ou "o dever da franqueza”. Os pressupostos da argumentação possuem um sentido performático, "são normativos num sentido transcendental" (Idem, p. 92), e não podem ser confundidos com obrigações morais pelo fato de que não podem ser transgredidos sistematicamente sem que o próprio jogo da argumentação seja destruído: são condições de possibilidade para a justificação das normas morais, valores e regras. O conteúdo normativo do jogo da argumentação representa um potencial de racionalidade que pode ser atualizado no uso público da razão, no exame crítico-reflexivo de diferentes pretensões de validade, sem estabelecer diretamente normas de ação, "mas critérios para um processo de aprendizagem que se corrige a si mesmo" (Idem, p. 99). A única coerção é a obrigação de assumir o "ônus de julgar" (burdens of judgment, na linguagem de Rawls) Esse potencial de racionalidade desenvolve-se em diferentes direções, dependendo do tipo de pretensão de validade que é tematizada e do correspondente tipo de discurso. O princípio do discurso, enquanto procedimento de teste intersubjetivo de justificação de normas de ação em geral, ainda não especifica quais tipos de razões são relevantes e convincentes e capazes de gerar acordos ou consensos. Expressa apenas um procedimento de justificação imparcial de normas e valores, que possibilita aos próprios indivíduos resolver suas controvérsias fazendo uso da razão prática em toda sua extensão: ${ }^{7}$ razões pragmáticas para fundamentar regras do agir instrumental que tem a ver com a escolha racional de meios e fins; razões éticas para orientações valorativas que se referem à vida boa, sobre o que quero ser ou o que queremos ser; razões morais para normas e princípios que se referem ao que é bom para todos os seres humanos sob a perspectiva da justiça. Esse procedimento não exclui de antemão o possível "potencial de verdade" de diferentes fundamentações (por

\footnotetext{
7 Talvez tenha-se aqui uma importante diferença entre a formalização do ponto de vista imparcial sugerida por Rawls no artifício hipotético da posição original e a reconstrução feita por Habermas. Ao contrário de Rawls, para Habermas a imparcialidade de juízos práticos pode ser alcançada em deliberações reais por indivíduos concretos, imersos nos processos de reprodução cultural, integração social e socialização do mundo da vida, sem recorrer ao dispositivo do "véu de ignorância". O princípio do discurso remete à reformulação intersubjetiva e procedimental do conceito kantiano de autonomia, e como tal não dá nenhuma orientação de conteúdo, mas apenas de procedimento, que deve assegurar a imparcialidade da formação do juízo. "É só com esse proceduralismo que a ética do discurso se distingue de outras éticas cognitivistas, universalistas e formalistas, tais como a teoria da justiça de Rawls [...] O princípio da ética do discurso proíbe que, em nome de uma autoridade filosófica, se privilegiem e se fixem de uma vez por todas numa teoria moral determinados conteúdos normativos (por exemplo, determinados princípios de justiça distributiva)" (HABERMAS, 1998:149).
} 
exemplo, religiosas ou seculares). A única exigência é que as diferentes contribuições ou posições tem de ser traduzidas numa linguagem comum acessível a todos, o que pode envolver custos de tradução para todos os envolvidos. Em princípio, num Estado democrático de direito a exigência de traduzibilidade é a mesma para todos os cidadãos, quaisquer que sejam seus interesses, valores ou convicções últimas. Mas, evidentemente, se observamos a dinâmica concreta de uma esfera pública mais ampla e a impregnação ética, sempre inevitável, das instituições do Estado democrático de direito, a exigência de traduzibilidade pode estar de fato distribuída assimetricamente entre os cidadãos - por exemplo, entre crentes e não crentes.

Diante disso, parece-me que o que uma filosofia social crítica pode oferecer para as democracias constitucionais marcadas pelo pluralismo legítimo é a reconstrução de um procedimento segundo o qual os próprios indivíduos podem chegar a uma avaliação imparcial das questões práticas fundamentais. É esse procedimento que é "formalizado" por Habermas no princípio do discurso. Do ponto de vista cognitivo, o princípio do discurso coloca em evidência o sentido das exigências de uma fundamentação pósconvencional e das condições de aceitabilidade racional, e do ponto de vista normativo, explicita o sentido da imparcialidade dos juízos práticos. Nada vem antes da prática de autodeterminação dos cidadãos, a não ser o princípio do discurso, que está inscrito nas condições de socialização comunicativa em geral e no próprio sistema de direitos fundamentais, constitutivo do Estado democrático de direito. O ponto de vista imparcial operacionalizado no princípio do discurso constitui um procedimento de teste, o "procedimento aberto de uma práxis argumentativa que se encontra sob os pressupostos exigentes do 'uso público da razão' e que não exclui de saída o pluralismo das convicções e visões de mundo" (HABERMAS, 1998, p. 54).

Voltando ao nosso problema dos limites da tolerância, sabemos agora quem deve estabelecê-los: são as próprias partes (indivíduos ou grupos) envolvidas nos conflitos. E devem fazê-lo recorrendo ao uso público da razão. Mas, não ficamos apenas com a virtude dos cidadãos e a normatividade fraca do princípio do discurso para resolver a questão ${ }^{8}$. Aqui, precisamos acompanhar o desdobramento do princípio do discurso na forma de um princípio da democracia, institucionalizado no próprio sistema de direitos das democracias constitucionais. Trata-se de ver como Habermas

${ }^{8}$ Isso não significa, é claro, que a tolerância como virtude pessoal seja dispensável. 
reconstrói a institucionalização jurídica (no vínculo interno entre sistema de direitos fundamentais e a soberania popular) do uso público da razão, encarregado de introduzir o ponto de vista da imparcialidade nos processos de formação da opinião pública e da vontade política. A exigência de uma justificação pós-metafísica decorre das próprias instituições do Estado democrático de direito. Sem essa exigência de imparcialidade não é possível pensar a legitimação do exercício do poder político, no qual os limites da tolerância são definidos. "O exercício de um poder que não consegue justificar-se de modo imparcial é ilegítimo porque, nesse caso, uma parte estaria impondo sua vontade a outra. Cidadãos de uma comunidade democrática devem apresentar, uns aos outros, argumentos porque somente assim o poder político perde seu caráter eminentemente repressivo" (HABERMAS, 2007, p. 138). Num Estado de direito democrático que precisa permanecer neutro do ponto de vista das diferentes doutrinas abrangentes, só valem como legítimas "as decisões políticas que puderem ser justificadas à luz de argumentos acessíveis em geral” (Idem, p. 138). Habermas pensa essas condições segundo o princípio da democracia cuja finalidade é "a amarrar um procedimento de normatização legítima do direito. Ele significa que somente podem pretender validade legítima as leis jurídicas capazes de encontrar o assentimento de todos os parceiros do direito num processo jurídico de normatização discursiva. O princípio da democracia explica, noutros termos, o sentido performativo da prática de autodeterminação de membros do direito que se reconhecem mutuamente como membros iguais e livres de uma associação estabelecida livremente" (HABERMAS, 1997, I, p. 145). O princípio da democracia pressupõe a possibilidade da decisão racional de questões práticas em geral, mais precisamente, refere-se à legitimação daquelas normas de ação que surgem sob a forma do direito. Como tal não é uma regra da argumentação: refere-se às condições abstratas de institucionalização da formação racional da opinião e da vontade, através de um sistema de direitos que garante a cada um igual participação no processo de normatização jurídica.

Segundo a reconstrução de Habermas, o princípio da democracia e o sistema de direitos não estão numa relação de subordinação, mas se pressupõem mutuamente. Existe uma co-originariedade e uma interdependência recíproca entre eles. O sistema de direitos aparece como o outro lado do princípio da democracia e este somente pode aparecer como o cerne de um sistema de direitos. O vínculo interno entre Estado de direito e 
democracia deliberativa (direitos humanos e soberania popular; autonomia privada e autonomia pública) aparece na reconstrução da gênese lógica do sistema de direitos. "O princípio da democracia só pode aparecer como núcleo de um sistema de direitos. A gênese lógica desses direitos forma um processo circular, no qual o código do direito e o mecanismo para a produção do direito legítimo, portanto, o princípio da democracia, se constituem de modo co-originário" (HABERMAS, 1997, I, p. 158). Esta gênese pode ser separada em dois estágios: o das condições de formalização jurídica da socialização horizontal em geral (sem o poder organizado do Estado) e o da formalização jurídica da relação vertical entre a prática de autodeterminação dos cidadãos e o poder político exercido na forma do Estado democrático de direito. $\mathrm{O}$ que Habermas demonstra nessa reconstrução é que o vínculo interno, do ponto de vista normativo, entre Estado de direito e a democracia deliberativa está pressuposto na própria estrutura reflexiva e características formais do direito moderno (direitos subjetivos, direito coativo e direito positivo)

O primeiro estágio da reconstrução do sistema de direitos fundamentais consiste em demonstrar a interligação entre o princípio do discurso e a forma jurídica moderna. Habermas (1997, I, p. 157) parte da formulação kantiana do princípio do direito: "a liberdade de cada um deve poder conviver com a igual liberdade de todos, segundo uma lei universal”. Segundo esta formulação, o direito obrigatório estende-se somente às relações externas entre pessoas e se dirige à liberdade de escolha de sujeitos que se orientam pelos seus próprios interesses e concepções do bem. A forma do direito moderno assegura o status de pessoa do direito mediante liberdades subjetivas de ação reclamáveis juridicamente e que podem ser usadas segundo o arbítrio de cada um. Mas, a ordem jurídica também tem de poder ser acatada por razões morais. Nesse sentido, o espaço legítimo de liberdade das pessoas de direito é determinado por meio de um esquema de iguais liberdades subjetivas de ação, assegurado por uma lei universal.

Não obstante, embora a forma do direito já esteja vinculada conceitualmente às liberdades subjetivas segundo uma lei universal da liberdade, ela mesma não consegue determinar nenhum direito. A expressão "lei universal" carrega todo o peso da legitimação. E diferente de Kant, a forma do direito exige, como direito positivo, "o papel de um legislador político pelo qual a legitimidade da legislação se explique mediante um procedimento democrático que assegure a autonomia política dos cidadãos. 
Os cidadãos são politicamente autônomos somente quando podem entenderse a si mesmos conjuntamente como autores daquelas leis a que se submetem como destinatários" (HABERMAS, 1998, p. 69). O que Habermas acredita que deve ser demonstrado é o argumento de que um sistema de direitos pode ser desenvolvido somente quando a forma jurídica adquirir expressão no procedimento da soberania popular, em cujo exercício os cidadãos especificam o que pode ser considerado como uma lei universal.

A forma do direito, portanto, não pode subsistir num estado de pureza transcendental: as liberdades subjetivas têm de ser configuradas e interpretadas pelos próprios cidadãos. Isso implica considerar o vínculo interno entre autonomia privada e pública, direito e democracia. "O princípio do discurso pode assumir através do medium do direito a forma de um princípio da democracia somente à medida que o princípio do discurso e o medium do direito se interliguem e desenvolvam num sistema de direitos que coloca a autonomia privada e pública numa relação de pressuposição mútua. E vice-versa, qualquer exercício da autonomia política significa ao mesmo tempo uma configuração concreta e interpretação destes direitos através de um legislador histórico" (HABERMAS, 1997 I, p. 165). Por um lado, não existe nenhum direito sem liberdades subjetivas de ação que assegurem a autonomia privada das pessoas de direito individuais. Por outro, não existe nenhum direito legítimo sem a legislação democrática comum dos cidadãos livres e iguais. Um é condição para o outro: o conteúdo normativo dos direitos de liberdade é condição para a institucionalização jurídica do uso público da razão dos cidadãos. Mas, ao mesmo tempo, só existem quando configurados e interpretados na própria razão pública ${ }^{9}$.

Desta ligação interna entre autonomia privada e pública segue-se que as questões de justificação da normatividade em geral, e a dos limites da tolerância em particular, não podem ser respondidas apenas pelo princípio

\footnotetext{
9 "Nada vem antes da prática de autodeterminação dos cidadãos, a não ser, de um lado, o princípio do discurso, que está inserido nas condições de socialização comunicativa em geral, e, de outro, o medium do direito. Temos de lançar mão do medium do direito caso queiramos implementar no processo de legislação - com o auxílio de iguais direitos de comunicação e de participação - o princípio do discurso como princípio da democracia. Entretanto, o estabelecimento do código jurídico enquanto tal já implica direitos de liberdade, que criam o status de pessoas do direito, garantindo sua integridade. No entanto, esses direitos são condições necessárias que apenas possibilitam o exercício da autonomia política: como condições possibilitadoras, eles não podem circunscrever a soberania do legislador, mesmo que estejam à sua disposição. Condições possibilitadoras não impõem limitações àquilo que constituem" (HABERMAS, 1997, I, p. 165).
} 
da soberania popular ou apenas recorrendo ao império das leis asseguradas pelos direitos individuais básicos. Habermas parte do fato de que a filosofia política não logrou dirimir de forma satisfatória a tensão entre soberania popular e direitos humanos, ou liberdade dos antigos e liberdade dos modernos. Para Habermas, essa tensão pode ser apaziguada quando se considera o procedimento democrático de legitimação política a partir do princípio do discurso. Sob as condições do pluralismo cultural, é o processo democrático que confere força legitimadora ao processo de criação do direito. "A almejada coesão interna entre direitos humanos e soberania popular consiste assim em que a exigência de institucionalização de uma prática cidadã do uso público das liberdades comunicativas seja cumprida justamente por meio dos direitos humanos. Direitos humanos que possibilitam o exercício da soberania popular não se podem impingir de fora, como uma restrição" (HABERMAS, 2002, p. 292).

Isso implica interpretar de outra maneira o sistema de direitos fundamentais ${ }^{10}$. Por um lado, o sistema de direitos não pode ser reduzido a uma interpretação moral, como querem os liberais ${ }^{11}$. Por outro, não pode ser simplesmente a expressão da autocompreensão ética da soberania popular, como reivindicam republicanos e comunitaristas. A autonomia privada dos cidadãos não pode ser sobreposta e nem subordinada à sua autonomia política.

$\mathrm{Na}$ reconstrução do vínculo interno entre estado de direito e democracia deliberativa, apresentada no nível de socialização horizontal da autodeterminação dos cidadãos, o argumento de Habermas consiste em ressaltar o sentido intersubjetivo dos direitos da cidadania democrática: são relações que têm sua base nas estruturas de reconhecimento recíproco, têm os mesmos pressupostos da racionalidade comunicativa. Os pressupostos quasi-

\footnotetext{
10 Habermas (1997, I, p. 159-160) apresenta cinco categorias de direitos: "direitos fundamentais que resultam da configuração politicamente autônoma do direito a maior medida possível de iguais liberdade subjetivas de ação; direitos que resultam da configuração politicamente autônoma do status de um membro numa associação voluntária de parceiros do direito; direitos fundamentais que resultam da possibilidade de acionar os direitos e da configuração politicamente autônoma da proteção judicial individual; direitos fundamentais à participação, em igualdade de oportunidades, em processos de formação da opinião e da vontade, nos quais os cidadãos exercitam sua autonomia política e através dos quais criam direito legítimo; direitos fundamentais a condições de vida garantidas social, técnica e ecologicamente, na medida em que isso for necessário para um aproveitamento, em igualdade de oportunidades, das quatro categorias de direitos anteriores".

11 "A reivindicação de legitimidade das normas jurídicas apóia-se sobre vários tipos de razões. A práxis legislativa justificadora depende de uma rede ramificada de discursos e negociações - e não apenas de discursos morais" (HABERMAS, 2002, p. 289).
} 
transcendentais das experiências de reconhecimento recíproco, vivenciadas no face a face da vida quotidiana e na forma reflexiva do discurso, estão incorporados no próprio sistema modero de direitos, que possibilita diferentes experiências de respeito e reconhecimento recíprocos entre indivíduos estranhos entre si, e que querem permanecer estranhos.

Retomando a questão dos limites da tolerância, os cidadãos terão de estabelecê-los respeitando a estrutura do sistema de direitos, a forma jurídica e seu vínculo interno com a democracia, o uso público da razão. Qualquer solução para o problema dos limites do tolerável/intolerável não pode suspender a lógica deliberativa e pública dos discursos práticos que legitimam as normas legais. Deve ser respeitado o universalismo procedimental da concepção liberal igualitária que caracteriza a cidadania democrática das comunidades políticas modernas.

Contudo, vale destacar que esta reconstrução se dá no nível conceitual, mas não há garantia de que isso vá necessariamente acontecer nas deliberações públicas efetivas. Trata-se de um pressuposto que confere sentido ao ideal de autodeterminação política dos cidadãos. Mas, "compete aos destinatários decidir se eles, enquanto autores, vão empregar sua vontade livre, se vão passar por uma mudança de perspectivas que os faça sair do círculo dos próprios interesses e passar ao entendimento sobre normas capazes de receber o assentimento geral, se vão ou não fazer um uso público de sua liberdade comunicativa, [ou seja], as instituições jurídicas da liberdade decompõem-se quando inexistem iniciativas de uma população acostumada à liberdade. Sua espontaneidade não pode ser forçada através do direito; ele se regenera através das tradições libertárias e se mantém nas condições associacionais de uma cultura política liberal” (HABERMAS, 1997, I, p. 167-168).

A cultura política liberal de um mundo da vida racionalizado é uma das condições essenciais à realidade efetiva da prática de justificação e do ideal normativo da democracia. Assim como o conceito de mundo da vida é complementar ao de ação comunicativa, pode-se dizer que a noção de cultura política comum é complementar ao conceito de discurso prático, como forma de apaziguar o risco do dissenso e assegurar alguma estabilidade da tensão entre facticidade e validade. Claro, os discursos práticos contam também com sua institucionalização no sistema de direitos. Todavia, Habermas não desconsidera o enraizamento do universalismo liberaligualitário do sistema de direitos na cultura política comum, que tem um apelo mais forte aos corações e mentes das pessoas. O uso público da razão (e 
sua tradução numa política deliberativa) passa tanto pela institucionalização dos procedimentos discursivos e a garantia do universalismo do sistema de direitos fundamentais quanto pelo enraizamento na autocompreensão éticopolítica cultural dos cidadãos membros de uma comunidade política, o que torna inevitável a impregnação ética de qualquer comunidade jurídica e de qualquer processo democrático de concretização dos direitos fundamentais. Isso implica, por sua vez, que nas democracias constitucionais modernas existe uma tensão insuperável na definição dos limites da tolerância: entre o universalismo (abstrato) dos direitos fundamentais (institucionalizados) de uma comunidade político-jurídica de cidadãos livres e iguais, e o particularismo dos cidadãos que se sentem membros de uma comunidade política concreta que compartilha valores, linguagem, tradições e narrativas comuns. É sempre uma coletividade política aqui e agora que toma as decisões. A reconstrução habermasiana dos pressupostos pragmáticos universais do discurso e do sistema de direitos mostra como as deliberações políticas nas democracias modernas operam sob o forte constrangimento procedimental de um uso público da razão que tem "o sentido inclusivo de uma prática de autolegislação que engloba igualmente todos os cidadãos. Inclusão quer dizer que a coletividade política permanece aberta para aceitar como membros os cidadãos de qualquer origem sem incorporar o outro na uniformidade de uma comunidade do povo homogênea" (HABERMAS, 2002:134-5).

"Permanecer aberta para aceitar" não significa que todas as crenças e formas de vida devem ser aceitas. Trata-se, antes, de reconhecer que embora funcione sob um critério forte de igualdade política de inclusão plena do outro, o uso público da razão nas sociedades democráticas contemporâneas também opera como um mecanismo de exclusão: nem todas as particularidades e diferenças podem ser reconhecidas, principalmente aquelas que se recusam a assumir as regras constitutivas do jogo político democrático - que são, em última instância, a institucionalização das próprias regras da razão comunicativa. O que é importante para a questão dos limites da tolerância é que a ideia de uso público da razão não nos autoriza a dizer de antemão, antes do jogo político, dizer quais posições são ou não são aceitáveis publicamente ${ }^{12}$. É sempre uma comunidade concreta de cidadãos aqui e agora que tem de definir os limites do tolerável/intolerável (e

${ }_{12}$ Claro, ficam excluídos os que negam o direito à justificação e os procedimentos do uso público da razão. 
apaziguar a tensão entre universalismo e particularismo) por meio do uso público da razão em toda sua extensão, incluindo uma multiplicidade de razões, e são toleráveis todas as razões que não anularem as dimensões criticoreflexivas, procedimentais, da democracia, vale dizer, a estrutura reflexiva do Estado de direito democrático. A democracia, para além de um mero regime político, só faz algum sentido como forma de vida se for entendida como um processo de aprendizagem contínuo que acolhe o conflito e as diferenças, configurando suas práticas e instituições num jogo (mediado juridicamente) de abertura e fechamento de seus limites à luz de razões aceitáveis por todos. É tolerável, em princípio, tudo o que não anular as condições procedimentais do jogo democrático: a primazia da "justiça” sobre o bem. É nesse sentido que a delimitação da justiça não é uma tarefa teórico-conceitual, mas sim prático-moral. Uma questão adicional é saber como essa ideia de uso público da razão é plausível historicamente, o que implica na elaboração mais precisa de um diagnóstico das patologias das sociedades modernas que exponha os obstáculos que impedem a realização do uso público da razão.

\section{Referências}

BOBBIO, N. A era dos direitos. Trad. Carlos Nelson Coutinho. Rio de Janeiro: Campus, 1992.

BROWN, W. "Reflexionen über Toleranz Im Zeitalter der Identität". In: FORST, R. (ed.). Toleranz. Frankfurt/M: Campus, 2000, p. 257-281.

FORST, R. Kontexte der Gerechtigkeit. Politische Philosophie jenseits von Liberalismus und Kommunitarismus. Frankfurt am Main: Suhrkamp, 1996. . "The Basic Right to Justification”, Constellations, v.6, 1996, p. $35-60$.

. Toleranz im Konflikt. Geschichte, Gehalt und Gegenwart eines umstrittenen Begriffs. Frankfurt/M: Suhrkamp, 2003.

- "Toleration, Justice and Reason". In: MCKINNON, C. e CASTIGLIONE, D. (eds.). The Culture of Toleration in Diverse Societies. Manchester: Manchester University Press, 2003.

. "The Limits of Toleration". In: Constellations, v.11, n.3, 312-325, 2004.

. "To Tolerate means to insult': toleration, recognition and emancipation”. In: VAN DEN BRINK, B., OWEN, D. (eds). Recognition 
and Power. Axel Honneth and the tradition of critical social theory. New York: Cambridge University Press, 2007.

HABERMAS, J. Consciência Moral e Agir Comunicativo. Tradução de Guido de Almeida. Rio de Janeiro: Tempo Brasileiro, 1989.

- "Vom pragmatischen, ethischen und moralischen Gebrauch der praktischen Vernunft". In: Habermas, Jürgen. Erläuterungen zur Diskursethik. Frankfurt: SuhrkamP, 1991.

. Faktizität und Geltung. Beiträge zur Diskurstheorie des Rechts und des demokratischen Rechtsstaats. Darmstadt: Wissenchaftliche Buchgesellschaft, 1994.

- "Reconciliation through the public use of reason: remarks on John Rawls political liberalism”. In: The Journal of Philosophy, XCII, n. 3, 1995.

- Direito e Democracia. Entre Facticidade e Validade. (v. I e II).

Trad. Flávio Sibeneichler. Rio de Janeiro: Tempo Brasileiro, 1997.

HABERMAS, J., RAWLS, J. Debate Sobre el Liberalismo Político. Barcelona: Paidós, 1998.

HABERMAS, J. A Inclusão do Outro. Estudos de teoria política. Tradução: George Sperber e Paulo Astor Soethe. São Paulo: Loyola, 2002.

. Entre Naturalismo e Religião. Estudos filosóficos. Trad. Flávio

Siebeneichler. Rio de Janeiro: Tempo Brasileiro, 2007.

KOSELLECK, R. Crítica e Crise: uma contribuição à patogênese do mundo burguês. Tradução do alemão de Luciana Villas-boas Castelo-Branco. Rio de Janeiro: EDUERJ/Contraponto, 1999.

MARCUSE, H. "Repressive Toleration”. In: Wolff, Robert P., Moore, B. e Marcuse, H. (eds.). A Critique of Pure Toleration. Boston: Beacon Press, 1965.

RAWLS, J. (1996). Political Liberalism. New York: Columbia University Press, 1996. . O Liberalismo Político. São Paulo: Ática, 2000. 